\title{
Unification of the Quadratic Model Equations of the Inhibition Characteristics of Acidified Ocimum Basilicum on the Corrosion Behaviour of Mild Steel
}

\author{
Michael O. Nwankwo ${ }^{1}$, Paul A. Nwobasi ${ }^{2}$, Peter O. Offor ${ }^{3}$, Ndubuisi E. Idenyi ${ }^{1}$ \\ ${ }^{1}$ Department of Industrial Physics, Ebonyi State University, Abakaliki, Nigeria \\ ${ }^{2}$ Department of Technology and Vocational Education, Ebonyi State University, Abakaliki, Nigeria \\ ${ }^{3}$ Department of Metallurgical and Materials Engineering, University of Nigeria, Nsukka, Nigeria \\ Email: michaelnwankwo@yahoo.com, awonwobasi@yahoo.com, peterjoyoffor@yahoo.com, edennaidenyi@yahoo.com
}

Received September 3, 2013; revised October 14, 2013; accepted October 23, 2013

Copyright (C) 2013 Michael O. Nwankwo et al. This is an open access article distributed under the Creative Commons Attribution License, which permits unrestricted use, distribution, and reproduction in any medium, provided the original work is properly cited.

\begin{abstract}
An attempt has been made at unifying the resulting quadratic models from the study of the correlation behavior of the inhibition characteristics of acidified ocimum basilicum on conventional mild steel. Weight-loss corrosion technique was employed in obtaining the corrosion penetration rate using the equation: $c p r=\frac{87.6 \Delta w}{\rho A t}$. Subsequently, the quadratic models were developed by using a computer-aided statistical modeling technique (International Business Machine (IBM)'s SPSS version 17.0). The results obtained showed a nearly perfect positive correlation with a correlation coefficient in the range of $0.986 \leq R \leq 0.996$ which depicts that $R \geq 1$. Also, the coefficient of determination fell within the range of $0.972 \leq R^{2} \leq 0.992$ showing that approximately $97 \%$ to $99 \%$ of the total variation in passivation rate was accounted for by corresponding variation in exposure time, leaving out only between $3 \%$ and $1 \%$ to extraneous factors that are not incorporated into the model equations. The equations were further unified into a generalized form using MathCAD 7.0 and the resulting equation was $y=1.032-0.002 t+1.899 \times 10^{-6} t^{2}$ with a $R^{2}$ value of 0.935 indicating a well-correlated relationship. With this, a new frontier on corrosion studies has emerged typifying a classical departure from previously long-held assumption that corrosion behaviours at room temperature were only logarithmic.
\end{abstract}

Keywords: Corrosion; Inhibition; Ocimum Basilicum; Correlation; Quadratic Models; Passivation

\section{Introduction}

Corrosion has been defined from the individual perspectives of several authors. However, most authors insist that the definition of corrosion should be restricted to metals. More often than not, though, corrosion engineers must consider both metals and nonmetals for solution of a given problem. Accordingly, polymers (plastics, rubbers, etc.), ceramics (concrete, brick, etc.) or composites (mechanical mixtures of two or more materials with different properties) and other nonmetallic materials are generally included as materials that can corrode [1].

Reference [2] defined corrosion as the environmentally induced degradation of a material that involves a chemical reaction. Degradation implies deterioration of physical properties of the material. This can be a weakening of the material due to a loss of cross-sectional area; it can be the shattering of a metal due to hydrogen embrittlement; or it can be the cracking of a polymer due to sunlight exposure.

The deleterious effects of corrosion are well-known and include among others: poor outward appearance of material surfaces, high maintenance and operating costs, frequent plant shutdowns, contamination of end products, loss of valuable products, hazardous effects on safety and reliability and burdensome product liabilities. As a result of these, huge financial losses have always been recorded annually as resulting from corrosion damage. As an instance, in 1998 alone, the United States reported an estimate of the cost of corrosion to be around $\$ 276$ billion: a figure that is however realistically put at $\$ 30$ billion [1]. In fact, [3] has gone further to project that this figure would reach $\$ 993$ billion by March 2013, with a still 
further increase to $\$ 1$ trillion by June of the same year.

It is against this backdrop of financial losses that corrosion engineers over the years have had to rely on the concept of materials selection and economics to mitigate corrosion. However, even with the proper selection of base metals and well-designed systems or structures, there is no absolute way to eliminate all corrosion. Therefore, corrosion protection methods are used to additionally mitigate and control the effects of corrosion. Corrosion protection can be in a number of different forms or strategies with perhaps multiple methods applied in severe environments [4]. The various forms of corrosion protection include among others the use of inhibitors, surface treatments, coatings and sealants, cathodic protection and anodic protection.

In recent times, however, the hazardous consequences of the somewhat traditional or conventional methods of corrosion control, has made it imperative to source for cost-effective and environmentally-friendly corrosion control measures to eliminate or at least reduce these effects. In this respect, the use of natural plants as corrosion inhibitors has expectedly become the current frontiers of most research activities in corrosion engineering. Inhibitors are chemicals that react with the surface of a material decreasing the material's corrosion rate, or that interact with the operating environment to reduce its corrosivity [4]. They can be added into the corrosion medium as solutions or dispersions to form a protective film, or as additives in coating products, or further still into waters used for washing vehicle, system or component. When added, they interact with the metal, thus slowing the corrosion process by shifting the corrosion potential of the metal's surface toward either the cathodic or anodic end; preventing permeation of ions into the metal; or increasing the electrical resistance of the surface [4].

Africa, and particularly Nigeria, with her favourable tropical climatic conditions is home to a vast number of natural plants that are continuously been investigated as profitable alternatives to synthetic inhibitors because of their inherent advantages amongst which are their ready availability, biodegradability, non-toxicity, non-pollutancy and eco-friendliness [5,6]. It is on the strength of these that ocimum basilicum was chosen for this work.

Ocimum basilicum is itself a vegetable plant believed to be of Indian origin [7-9]. It belongs to a popular plant species called basil. There are several varieties of basil in existence, some of which have been used in previous works [10-13]. However, basilicum species have not been investigated previously in relation to mild steel to the best of the authors' knowledge.

Reference [14] used statistical tools (particularly regression analysis) as a novel approach in corrosion studies. Since then, several other works have been done to develop models for predicting the corrosion behavior of engineering materials using specific parameters [15-18]. The findings from these works show that corrosion profiles correlated better in the quadratic models than the logarithmic models at room temperatures.

This work therefore is an attempt to reinforce the findings of [14] with regards to the regression behavior of corrosion rates at room temperatures; and then unifying the resultant regression equations into a single model equation that would satisfy the conditions as a framework for futuristic corrosion predictions particularly during design considerations.

\section{Experimental Techniques}

\subsection{Materials/Equipment}

The materials and equipment used for the work include $10 \mathrm{~mm}$ diameter mild steel rods sourced from a local steel stockiest in Enugu, Nigeria, beakers, digital weighing balance, tetraoxosulphate (VI) acid, leaves of ocimum basilicum, acetone, nylon strings, emery cloth, distilled water, hacksaw, vernier caliper, measuring cylinder, and volumetric flask.

\subsection{Materials Preparation}

The mild steel rods were cut to sizes, each averaging $94.5 \mathrm{~cm}^{2}$ in surface area. They were thoroughly brushed with emery cloth to reveal the metal surface. Thereafter, they were washed with distilled water and rinsed with acetone.

The tetraoxosulphate (VI) acid was prepared to $0.5 \mathrm{M}$ and 1.0 M concentrations using standard procedures.

The ocimum basilicum leaves were washed with cold tap water, dried under room temperature after which they were subjected to soxhlet extraction process in ethanol for about 80 hours to obtain the extract.

\subsection{Experimentation}

The mild steel coupons were tied with nylon strings and then suspended in beakers containing the acid and the acidified extracts. Each beaker contained 5 coupons and the entire set up were allowed to stand for 30 days. After 6 days a coupon was withdrawn from each beaker, rinsed in distilled water and swabbed in acetone. Thereafter, they were weighed for weight loss determination and corrosion rate calculation using the formula:

$$
c p r=\frac{87.6 \Delta w}{\rho A t} .
$$

The $\mathrm{pH}$ value of the ocimum basilicum extract was evaluated and noted.

\subsection{Unification of the Model Equations}

Using MathCAD 7.0, the model equations were plotted 
and the best line of fits was taken. The equation corresponding to this line was then noted with all of its necessary parameters.

\section{Results}

Tables 1-6 show the corrosion penetration rate values obtained from weight loss measurements; while Figures $\mathbf{1}$ and $\mathbf{2}$ are the quadratic model fits from regression analysis of the corrosion penetration rates. Table 8 is the quadratic model equations obtained from the regression analysis.

\section{Discussion}

\subsection{Corrosion Trends}

Looking at Tables 1-6, the corrosion rates obtained depict those of passivating metals: beginning with an initial steep rise, peaking at a maximum and then subsequently decreasing as exposure time increased. On interaction with the corrosion medium, the metal surface normally reacts swiftly with it, forming an oxide film that coats the entire surface acting as a barrier, thereby preventing further reactions [19].

Table 1. Corrosion penetration rates of mild steel sample in $0.5 \mathrm{~m} \mathrm{H}_{2} \mathrm{SO}_{4}$.

\begin{tabular}{|c|c|c|c|c|}
\hline Exposure time (hrs) & Initial weight (g) & Final weight (g) & Weight loss (g) & Corrosion rate $(\mathrm{mm} / \mathrm{yr})$ \\
\hline 144 & 26.76 & 20.46 & 6.30 & 0.5178 \\
\hline 288 & 26.34 & 19.59 & 6.75 & 0.2774 \\
\hline 576 & 26.51 & 19.00 & 7.51 & 0.1543 \\
\hline 720 & 27.01 & 15.93 & 11.11 & 0.1826 \\
\hline
\end{tabular}

Table 2. Corrosion penetration rates of mild steel sample in $0.5 \mathrm{~m} \mathrm{H}_{2} \mathrm{SO}_{4}$ with $25 \mathrm{~cm}^{3}$ of ocimum basilicum.

\begin{tabular}{ccccc}
\hline Exposure time (hrs) & Initial weight (g) & Final weight (g) & Weight loss (g) & Corrosion rate (mm/yr) \\
\hline 144 & 25.14 & 19.04 & 6.10 & 6.53 \\
288 & 28.82 & 22.29 & 6.5013 \\
432 & 28.36 & 21.80 & 0.2683 \\
576 & 27.61 & 20.67 & 0.1767 & 9.10 \\
720 & 26.90 & 17.80 & 0.1422 \\
\hline
\end{tabular}

Table 3. Corrosion penetration rates of mild steel sample in $0.5 \mathrm{~m} \mathrm{H}_{2} \mathrm{SO}_{4}$ with $50 \mathrm{~cm}^{3}$ of ocimum basilicum.

\begin{tabular}{ccccc}
\hline Exposure time (hrs) & Initial weight (g) & Final weight (g) & Weight loss (g) & Corrosion rate (mm/yr) \\
\hline 144 & 28.02 & 22.46 & 5.56 & 0.4560 \\
288 & 27.24 & 21.05 & 6.19 & 0.2544 \\
432 & 27.93 & 21.63 & 6.30 & 0.1745 \\
576 & 27.41 & 20.36 & 7.08 & 0.1444 \\
720 & 27.38 & 17.38 & 10.00 & 0.1454 \\
\hline
\end{tabular}

Table 4. Corrosion penetration rates of mild steel sample in $1.0 \mathrm{~m} \mathrm{H}_{2} \mathrm{SO}_{4}$.

\begin{tabular}{ccccc}
\hline Exposure time (hrs) & Initial weight (g) & Final weight (g) & Weight loss (g) & Corrosion rate (mm/yr) \\
\hline 144 & 25.70 & 14.84 & 10.86 & 0.8926 \\
288 & 25.64 & 12.69 & 12.95 & 0.5322 \\
432 & 25.50 & 12.35 & 13.15 & 0.3603 \\
576 & 24.47 & 9.82 & 14.65 & 0.2900 \\
720 & 26.63 & 10.63 & 16.00 & 0.2630 \\
\hline
\end{tabular}

Table 5. Corrosion penetration rates of mild steel sample in $1.0 \mathrm{~m} \mathrm{H}_{2} \mathrm{SO}_{4}$ with $25 \mathrm{~cm}^{3}$ of ocimum basilicum.

\begin{tabular}{ccccc}
\hline Exposure time (hrs) & Initial weight (g) & Final weight (g) & Weight loss (g) & Corrosion rate (mm/yr) \\
\hline 144 & 26.58 & 17.03 & 9.55 & 0.7849 \\
288 & 26.40 & 16.36 & 10.04 & 0.4126 \\
432 & 26.81 & 15.53 & 11.28 & 0.3090 \\
576 & 24.80 & 12.69 & 12.11 & 0.2488 \\
720 & 25.10 & 6.08 & 17.02 & 0.2305 \\
\hline
\end{tabular}


Table 6. Corrosion penetration rates of mild steel sample in $1.0 \mathrm{~m} \mathrm{H}_{2} \mathrm{SO}_{4}$ with $50 \mathrm{~cm}^{3}$ of ocimum basilicum.

\begin{tabular}{ccccc}
\hline Exposure time (hrs) & Initial weight (g) & Final weight (g) & Weight loss (g) & Corrosion rate (mm/yr) \\
\hline 144 & 27.71 & 18.42 & 9.29 & 0.7635 \\
288 & 27.22 & 16.85 & 10.37 & 0.4261 \\
432 & 26.86 & 15.29 & 11.57 & 0.3170 \\
576 & 25.19 & 12.97 & 12.22 & 0.2318 \\
720 & 24.73 & 10.63 & 14.10 & 0.2511 \\
\hline
\end{tabular}

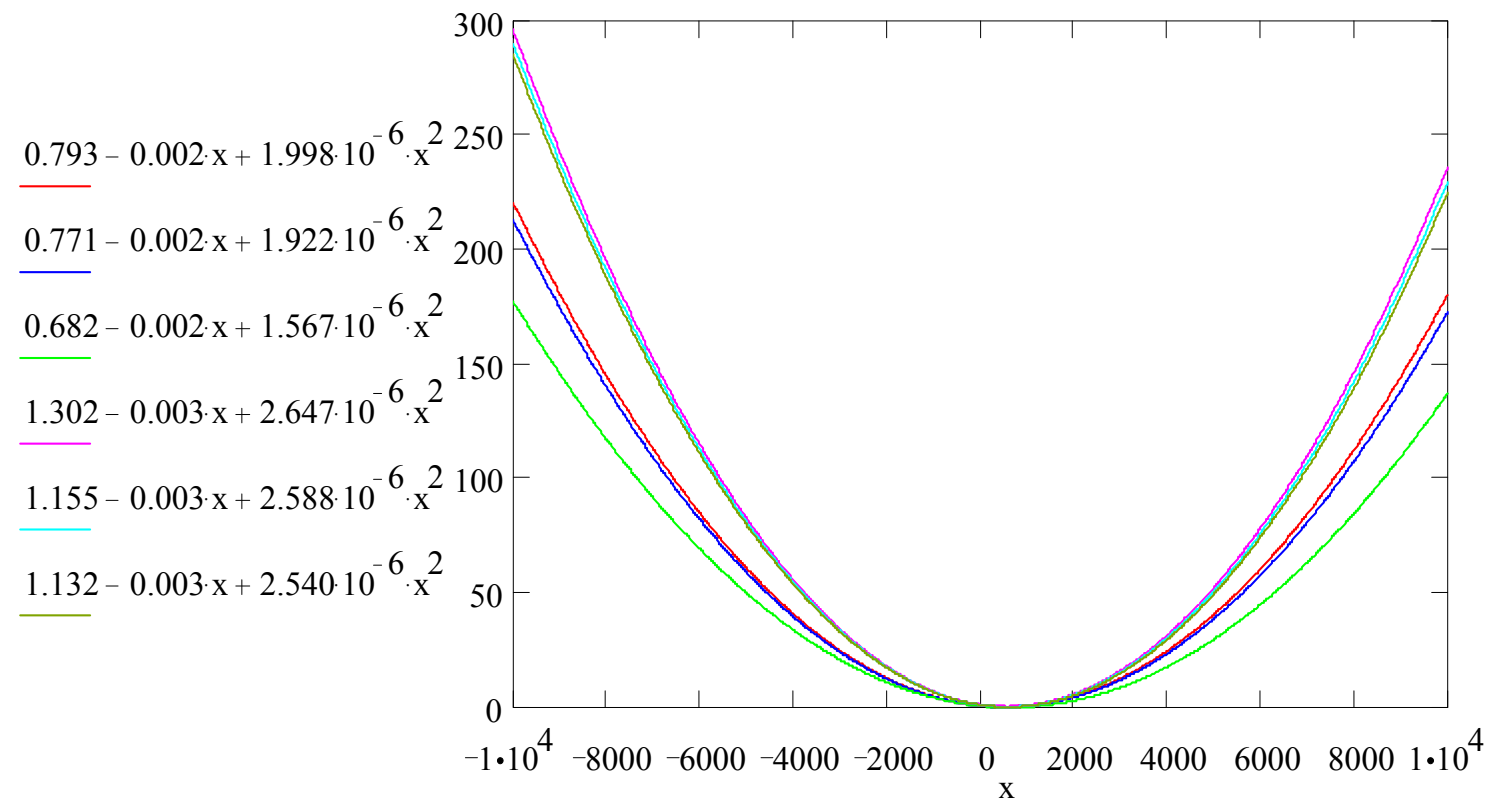

Figure 1. Graphical plots of the quadratic model equations using mathcad 7.0.

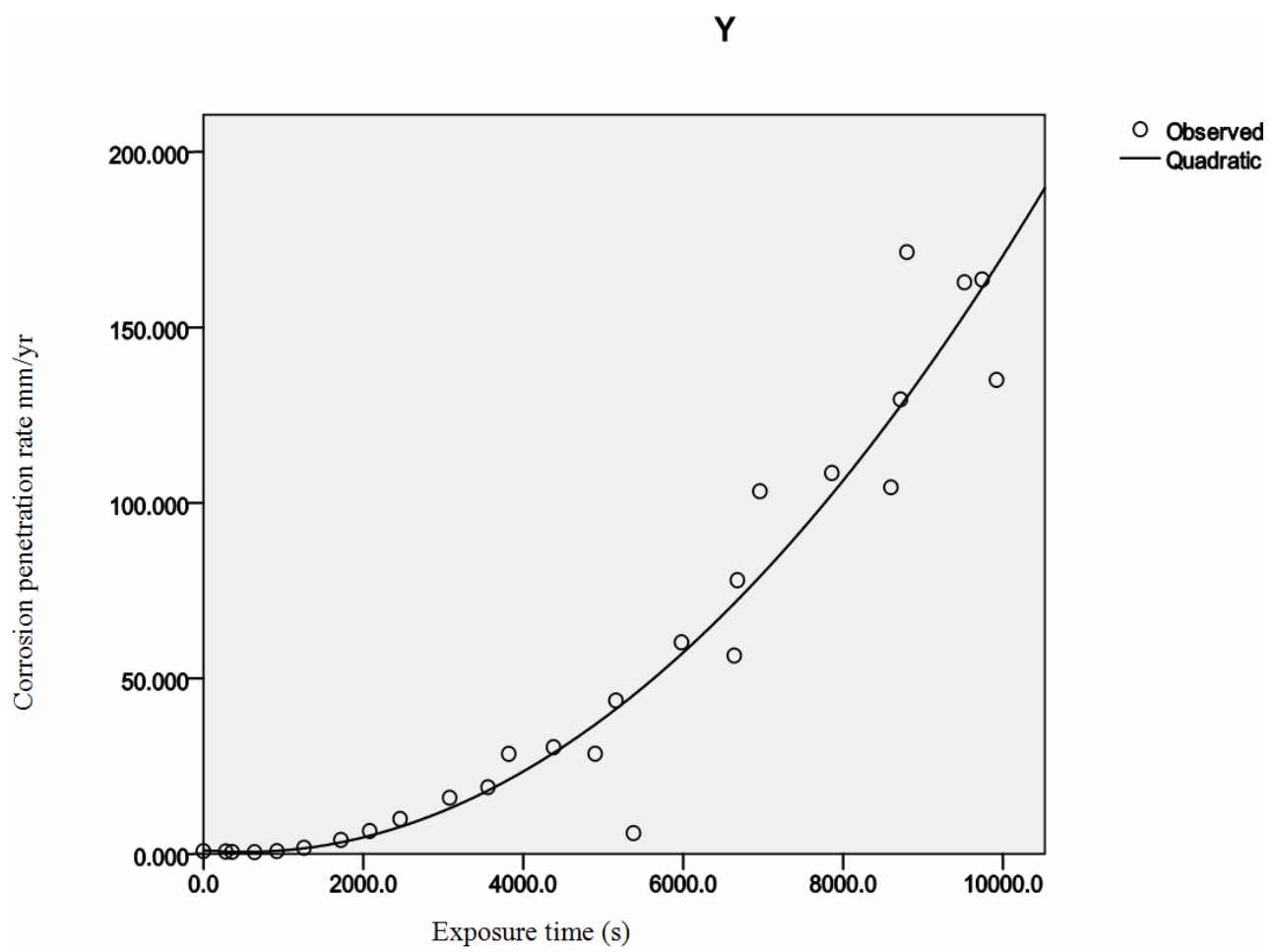

Figure 2. Line of best fits from the model equations. 


\subsection{Model Summary}

From Table 7, it can be seen that $R$ (coefficient of correlation) values ranged from 0.986 to 0.996 showing that $R$ $\geq 1$, which is a near-perfect correlation; while the $R^{2}$ (coefficient of determination) values ranged from 0.972 to 0.992 , implying that approximately between $97 \%$ to $99 \%$ of the entire variation in passivation rate is dependent on exposure time, leaving only a maximum of $3 \%$ to extraneous sources such as errors of measurements, experimental procedures and test locations.

Also, the standard error of estimation fell between $0.021-0.054$ which is significantly less than 0.1 . The implication of this very narrow error margin is that the use of quadratic models to characterize corrosion rates at room temperature is justifiable and therefore could be employed. That being the case, a classical departure from the long-held assumptions that corrosion rate behaviours are only logarithmic at room temperatures has been established.

These claims are corroborated by the line patterns of Figure 1 where the lines of best fits agree with the near perfectness of the correlation data obtained.

\subsection{Model Equations}

From Table 8, the model fit equations show that each had a non-negligible quadratic element that must be accounted for during corrosion rate evaluation. Since time and media are critical considerations in corrosion moni- toring, for a given medium therefore the exposure time becomes the overriding factor for corrosion progression, hence our time-dependent quadratic models subsist in this present study.

Furthermore, looking at the equations in the order in which they appeared, both the constant term and the coefficient of $t^{2}$ decreased as the volume of the extracts increased in each of the acid molarities. This confirms further that inhibition has taken place and that an increase in the inhibitor concentration caused a decrease in corrosion penetration rate.

\subsection{Unified Model Equation}

From Figure 2 we see the best line of fits from the plots of all the model equations represented in Table $\mathbf{8}$ and as plotted in Figure 1. The model parameters in Table 9 clearly show that the coefficient of determination, $R^{2}$ of 0.935 is very high indicating in similar manner that about $94 \%$ of the determining factors are dependent on exposure time of the corrosion process, whilst $6 \%$ is account-ed for by extraneous factors which in this case may include errors of mathematical measurements and evaluations. Based on the foregoing, the unified model equation

$$
c p r=1.032-0.002 t+1.899 \times 10^{-6} t^{2}
$$

is adjudged a suitable and correct corrosion predictor for the present study.

Table 7. Model equations of the various quadratic fits.

\begin{tabular}{cc}
\hline Corrosion medium & Model equations \\
\hline $0.5 \mathrm{M} \mathrm{H}_{2} \mathrm{SO}_{4}$ only & $0.793-0.002 t+1.998 \times 10^{-6} t^{2}$ \\
$0.5 \mathrm{M} \mathrm{H}_{2} \mathrm{SO}_{4}+25 \mathrm{~cm}^{3}$ ocimum basilicum & $0.771-0.002 t+1.922 \times 10^{-6} t^{2}$ \\
$0.5 \mathrm{M} \mathrm{H}_{2} \mathrm{SO}_{4}+50 \mathrm{~cm}^{3}$ ocimum basilicum & $0.682-0.002 t+1.567 \times 10^{-6} t^{2}$ \\
$1.0 \mathrm{M} \mathrm{H}_{2} \mathrm{SO}_{4}$ only & $1.302-0.003 t+2.647 \times 10^{-6} t^{2}$ \\
$1.0 \mathrm{M} \mathrm{H}_{2} \mathrm{SO}_{4}+25 \mathrm{~cm}^{3}$ ocimum basilicum & $1.155-0.003 t+2.588 \times 10^{-6} t^{2}$ \\
$1.0 \mathrm{M} \mathrm{H}_{2} \mathrm{SO}_{4}+50 \mathrm{~cm}^{3}$ ocimum basilicum & $1.132-0.003 t+2.540 \times 10^{-6} t^{2}$ \\
\hline
\end{tabular}

Table 8. Model parameters.

\begin{tabular}{ccccc}
\hline Corrosion Medium & \multicolumn{3}{c}{ Parameters } \\
\cline { 2 - 5 } $0.5 \mathrm{M} \mathrm{H}_{2} \mathrm{SO}_{4}$ & $R$ & $R^{2}$ & Adjusted $R^{2}$ & Standard Error of Estimation \\
\hline $0.5 \mathrm{M} \mathrm{H}_{2} \mathrm{SO}_{4}+25 \mathrm{~cm}^{3}$ Ocimum basilicum & 0.994 & 0.988 & 0.976 & 0.023 \\
$0.5 \mathrm{M} \mathrm{H}_{2} \mathrm{SO}_{4}+50 \mathrm{~cm}^{3}$ Ocimum basilicum & 0.995 & 0.990 & 0.980 & 0.021 \\
$1.0 \mathrm{M} \mathrm{H}_{2} \mathrm{SO}_{4}$ & 0.994 & 0.988 & 0.975 & 0.021 \\
$1.0 \mathrm{M} \mathrm{H}_{2} \mathrm{SO}_{4}+25 \mathrm{~cm}^{3}$ Ocimum basilicum & 0.996 & 0.992 & 0.984 & 0.033 \\
$1.0 \mathrm{M} \mathrm{H}_{2} \mathrm{SO}_{4}+50 \mathrm{~cm}^{3}$ Ocimum basilicum & 0.986 & 0.972 & 0.944 & 0.054 \\
\hline
\end{tabular}


Table 9. Model summary and parameter estimates of the unified equation.

\begin{tabular}{|c|c|c|c|c|c|c|c|c|}
\hline \multicolumn{9}{|c|}{ Dependent Variable: Y } \\
\hline \multirow{2}{*}{ Equation } & \multicolumn{5}{|c|}{ Model Summary } & \multicolumn{3}{|c|}{ Parameter Estimates } \\
\hline & $R$ Square & $\mathrm{F}$ & df1 & df2 & Sig. & Constant & b1 & $\mathrm{b} 2$ \\
\hline Quadratic & 0.935 & 171.551 & 2 & 24 & 0.000 & 1.032 & -0.002 & $1.889 \mathrm{E}-6$ \\
\hline \multicolumn{9}{|c|}{ The independent variable is $T$. } \\
\hline
\end{tabular}

Regression Equation: $\quad y=1.032-0.002 t+1.899 \times 10^{-6} t^{2}$.

\section{Conclusion}

The conclusion that can be drawn from the foregoing discussions is that ocimum basilicum is a good corrosion inhibitor since its $\mathrm{pH}$ value of 6.7 falls within the region in which passivation occurs in the Poubaix diagram [20]. Again the quadratic model which fits each with a nearly perfect correlation suggest in strong terms that room temperature corrosion progression can no longer be said to be only logarithmic but also has a significant quadratic part that must be accounted for during corrosion characterizations. Additionally, the unification of the model equations into a single generalized form also shows that it is henceforth possible and accurately so, to use the equation to make futuristic computations of corrosion penetration rates for engineering mild steel in acidic environments with ocimum basilicum serving as a veritable inhibitor.

\section{Acknowledgements}

The authors wish to acknowledge the Department of Industrial Chemistry of Ebonyi State University for granting them the permission to use their facilities for the work. Dr. S. O. Maliki of the Department of Industrial Mathematics, Ebonyi State University is also acknowledged for his immense contributions.

\section{REFERENCES}

[1] M. G. Fontana, "Corrosion Engineering," Tata McGrawHill Publishing Company Ltd., New Delhi, 2005.

[2] D. J. Duquette and R. E. Schafrik, "Research Opportunities in Corrosion Science and Engineering," National Academy of Sciences, Washington DC, 2011.

[3] G2MTLabs, "Cost of Corrosion in 2013 in the United States Exceeds \$1 Trillion,” 2011.

http://www.g2mtlabs.com/2011/06/nace-cost-of-corrosio n-study.update/

[4] B. D. Craig, R. A. Lane and D. H. Rose, "Corrosion Prevention and Control: A Program Management Guide for Selecting Materials," Alion Science and Technology, New York, 2006.

[5] A. Boxer and P. Back, "The Herb Book," Octopus Books Ltd., London, 1980.

[6] J. A. Duke, "Culinary Herbs: A Potpourri," Bouch Maga- zine Ltd., New York, 1985.

[7] N. Kumpawat, A. Chaturvedi and R. K. Upadhyay, "Comparative Study of Corrosion Inhibition Efficiency of Naturally Occurring Ecofriendly Varieties of Holy Basil (Tulsi) for Tin in $\mathrm{HNO}_{3}$ Solution," Open Journal of Metals, Vol. 2, No. 3, 2012, pp. 68-73. http://dx.doi.org/10.4236/ojmetal.2012.23010

[8] W. C. Muenscher and M. A. Rice, "Garden Spice and Wild Pot-Herbs," Cornell University Press, New York, 1978.

[9] T. Stobart, "Herbs, Spices and Flavorings," The Overbook Press, New York, 1982.

[10] H. Ashassi-Sorkhabi, B. Shabani, B. Aligholipour and D. Seifzadeh, "The Effect of Some Schiff Bases on the Corrosion of Aluminum in Hydrochloric Acid Solution," Applied Surface Sciences, Vol. 252, No. 12, 2006, pp. 40394047. http://dx.doi.org/10.1016/j.apsusc.2005.02.148

[11] O. K. Abiola, N. C. Okafor, E. E. Ebenso and N. M. Nwinuka, "Ecofriendly Corrosion Inhibitors: The Inhibitive Actions of Delonix Regia Extract for Corrosion of Aluminum in Acidic Media," Anticorrosion Methods and Materials, Vol. 54, No. 4, 2007, pp. 219-224. http://dx.doi.org/10.1108/00035590710762357

[12] N. Kumpawat, A. Chaturvedi and R. K. Upadhyay, "Comparative Study of Corrosion Inhibition Efficiency of Stem and Leaves Extract of Ocimum Sanctum (Holy Basil) for Mild Steel in $\mathrm{HCl}$ Solution," Protection of Metals and Physical Chemistry of Surfaces, Vol. 46, No. 2, 2010, pp. 267-270.

[13] J. A. Soule, "Father Kino's Herbs: Growing and Using Them," Tierra del sol Institute Press, Tucson, 2011.

[14] C. E. Ekuma and N. E. Idenyi, "Statistical Analysis of the Influence of Environment on Prediction of Corrosion from Its Parameters," Research Journal of Physics, Vol. 1, No. 1, 2007, pp. 27-34. http://dx.doi.org/10.3923/rjp.2007.27.34

[15] C. E. Ekuma, N. E. Idenyi and I. O. Owate, "Application of Statistical Technique to the Analysis of Passivation of Al-Zn Alloy Systems in Brine," Journal of Chemical Engineering and Materials Science, Vol. 1 No. 1, 2010, pp. $1-7$.

[16] C. I. Nwoye, N. E. Idenyi and J. U. Odo, "Predictability of Corrosion Rates of Aluminum-Manganese Alloys Based on Initial Weights and Exposure Time in Atmosphere," Nigerian Journal of Materials Science and Engineering, Vol. 3, No. 1, 2012, pp. 8-14.

[17] M. O. Nwankwo, P. A. Nwobasi, S. I. Neife and N. E. 
Idenyi, "Statistical Studies of the Inhibition Characteristics of Acidified Ocimum Basilicum on Engineering Mild Steel," Journal of Metallurgical Engineering, Vol. 2, No. 4, 2013, in press.

[18] C. Nwoye, S. Neife, E. Ameh, A. Nwobasi and N. Idenyi, "Predictability of Al-Mn Alloy Exposure Time Based on Its As-Cast Weight and Corrosion Rate in Sea Water Environment," Journal of Minerals and Materials Charac- terization and Engineering, 2013, in press.

[19] W. D. Callister, "Materials Science and Engineering: An Introduction," John Wiley and Sons Inc., New York, 1997.

[20] M. C. N. Ijomah, "Elements of Corrosion and Protection Theory," Auto-Century Publishing Company Ltd., Enugu, 1991. 